\title{
Cloud Computing Application in Education
}

\author{
Pragati Priyadarshinee
}

\begin{abstract}
The aim of the study is doing the classification of research articles on Cloud computing adoption in education sector through meta-analysis based on number of articles in different geographical location, year of publication, types of methodology, frameworks used and research area covered in last 9 years. In total 143 research articles from 27 peer-reviewed journals from the year 2010 to 2018 were used for meta-analysis. The research findings from the meta-analysis show there is a very little study in the area of cloud computing application in education. The study contributes to the body of knowledge by identifying a classification method for research methodology types, geographical area, articles published in last nine years, types of research framework and research area through meta-analysis.
\end{abstract}

Keywords: Cloud computing adoption; Meta-analysis; Education Sector

\section{INTRODUCTION}

Cloud computing adoption for developing countries will open a new future. Abdollahzadehgan et al. (2013) explained cloud computing as storage from larger datacentres to small scale data-centres. Before adopting cloud computing for any organization risk factors should be taken into account. Investors try to reduce the uncertainty in the process of business by dropping the profit level. Institutional data should be analysed in a structured manner. Only technical analysis was not sufficient in Indian universities. Innovation in Universities is required to fit outer location. Sultan (2010) stated that cloud computing leads to the IT commercialization. Data can be stored outside the Universities by public cloud. Cloud computing service provider can be from the same or other country. It would raise various risk factors for the privacy and security of data.

Cloud computing gives sophisticated technologies as India is a developing country. Cloud computing adoption would be an advantage for Universities across India to operated higher level of technologies with less expertise. It is expected that cloud would replace out-dated computing with the help of data centres with reduced cost as per the business requirement (Sultan, 2010). Out of all the definitions provided for cloud computing, widely accepted definition is given by NIST (National Institute of Standards and Technology). The paper constitutes of introduction in section 1 , literature review process in section 2 , journal classification

Revised Manuscript Received on December 30, 2019.

* Correspondence Author

Pragati Priyadarshinee, Department of Information Technology, BVRIT Hyderabad College of Engineering for Women, Hyderabad, India. Email: priyadarshinee.pragati@gmail.com

(C) The Authors. Published by Blue Eyes Intelligence Engineering and Sciences Publication (BEIESP). This is an open access article under the CC BY-NC-ND license (http://creativecommons.org/licenses/by-nc-nd/4.0/) method in section 3 , section 4 gives research findings and section 5 concludes with future scope of the study.

\section{LITERATURE REVIEW PROCESS}

According to Sabi et al. (2016) developing countries are left behind due to lack of technology adoption and implementation concept. The technology adoption factors include infrastructure, cost, knowledge, governmental policies, education and some security concerns. Economic growth between developed and developing countries is dependent on the appropriate technology adoption methods (Svantesson \& Clarke, 2010, Kshetri, 2010, Moodley, 2003). In the developing countries, companies like IBM establishing cloud computing centres. Kshetri (2010) identified the other cloud provider companies like Amazon, Microsoft, Salesforce and Dell are actively searching for opportunities to settle cloud centres in the developing countries. The developing economies of the developing countries can improve that will benefit the customers as a whole in terms of IT infrastructure, data centres and applications.

The IT infrastructure cost is very high that led so many universities to be behind in technological advancements of ICT infrastructure in comparison to the developed countries. Cost can be reduced by adopting new technologies by the universities that can be competitive with the western developed countries. Sultan (2010) stated about the Universities in western developed countries that have forced by the recent economic to adopt cloud computing for cost reduction. There is still a very slow pace of Indian Universities towards technology adoption which can lead good research, collaboration and teaching capabilities. Academic literatures review on cloud computing identified the gaps about the factors influencing the university decision. Less research work is there for cloud computing adoption frameworks in Indian universities (Sabi et al., 2016).

Private cloud which is also known as internal cloud can be used by the universities. Mohsin (2012) stated that only stakeholders can access all the private clouds. Usually, organizations own public cloud where resources are available via web-service. Qi et al. (2010) stated that public cloud is having lesser security as it doesn't have control over data. Kuyoro (2011) stated that Hybrid cloud is more secure than any other cloud because of its grants for different party access information over the internet technology. Technology adoption is one of the important areas of cloud computing. It is restricted to a particular direction of Indian Universities. The databases searched for the research article are EBSCO host and Proquest online. The review process is classified into four areas based on the meta-analysis: research methodology (78), year of publication (217), geographical area (196), research frameworks (243) and research area (99).

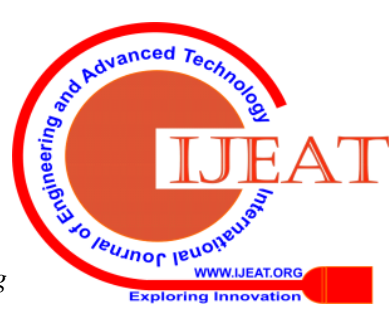




\section{JOURNAL CLASSIFICATION METHOD}

In the field of management meta-analysis plays an important role. Meta-analysis application is usually narrow. It is a systematic qualitative review of the literature that has a quantitative way of summarization. The meta-analysis poses a lot of questions; this is the reason why the researchers study on certain topic of interest. Judge et al. (2001) stated that in meta-analysis any constructs findings can be summarized empirically. Meta-analysis assesses a single association at a time between two variables. Researchers usually study frequently the strengths of the relationships among the factors. As per Bergh et al. (2016) meta-analysis is unable to deliver higher-level of analysis like comparing and integrating multiple models. But, this technique has been used very effectively for literature review. According to Shaw and Ertug (2017) there are three ways of meta-analysis technique. The basic way of literature review is electronic database search in information system (IS) research. So, it is an appropriate way of database search. The literature was searched in two ways. First one is the high-level IS journals in cloud computing to check the technicality which having very less results showing few journal articles. Second one is the wider search from different databases like Ebscohost, Proquest, Emerald, ScienceDirect, Sage, Google scholar and ACM Digital Library (Senyo et al., 2018; Yang \& Tate, 2012).

Levy and Ellis (2006) stated that the sources cover top 50 IS journals which requires a fair representation. The literature was searched with the key words "Cloud computing adoption", "Education sector", "Universities" and "TOE". The search was peer-reviewed journal articles from 2010 to 2018. The articles were filtered by reading the abstracts where reports, working papers, and reviews of books were removed. Articles from other disciplines were also removed. Total 196 research articles from 37 journals were classified and analysed based on the four classification themes: number of articles based on geographical location, year of publication, types of methodology and frameworks used. Classification of four types of methodology is qualitative, quantitative, mixed method and no method (Duncombe \& Boateng, 2009; Johnson \& Onwuegbuzie, 2004). Qualitative research articles include thematic analysis, grounded theory and case-based research. The data collection for qualitative study is usually done through observation and interviews. Survey data collection comes under quantitative study for which questionnaire framing is an integral part.

\section{RESEARCH FINDINGS}

The research articles were reviewed and classified into five major areas through meta-analysis.

\section{Classification Process}

The Classification of articles is filtered on four different aspects: research methodology, year of publication, geographical area, research frameworks and research area (Priyadarshinee et al., 2015)

\section{A. Research Methodology}

Number of research articles based on the four types of research methodologies is identified as given in the following bar-chart.

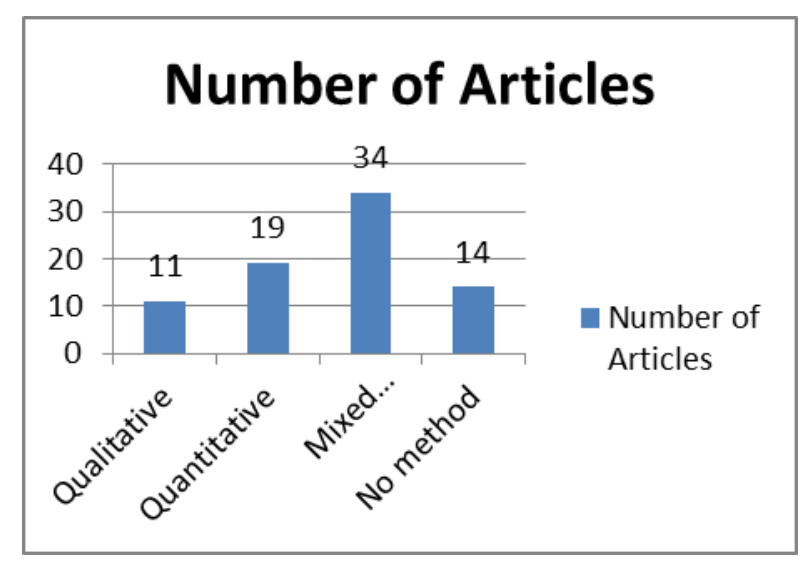

Figure 1: Classification of articles based on Research Methodologies

Figure 1 show the article classification based on the research methodologies used. There are four types of methodologies: mixed-method, qualitative, quantitative and no method. Mixed method is having highest number of articles (34), then quantitative (19), no method (14) and qualitative (11) articles in the area of cloud computing applications in education.

\section{B. Year of Publication}

The following pie-chart shows the classification of articles based on the year of publication.

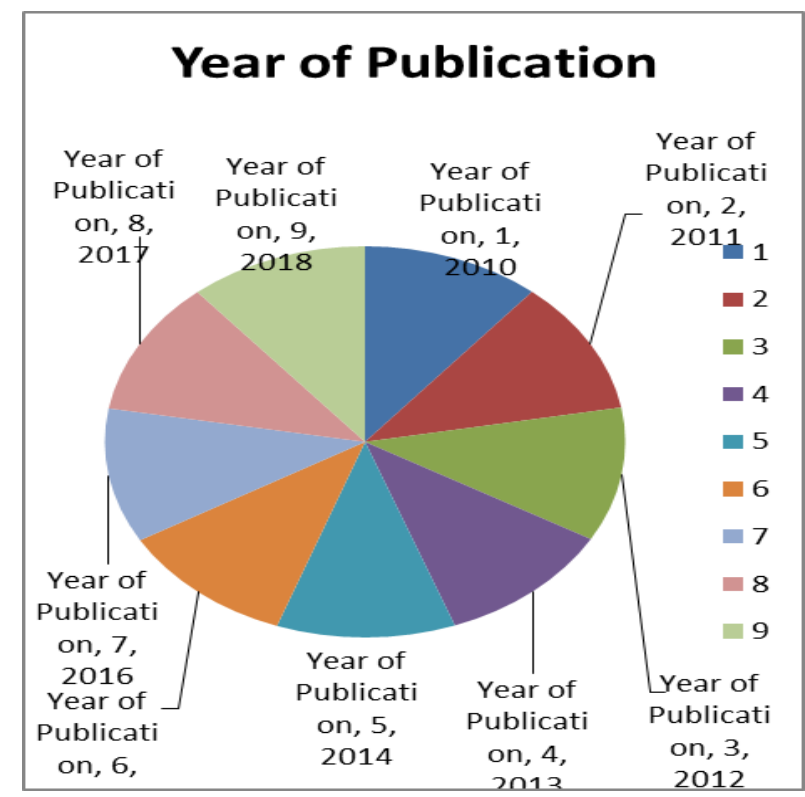

Figure 2: Classification of articles based on year of publication

Figure 2 shows highest number of articles (31) published in the year 2016 and lowest number of articles (16) published in 2011 in the area of cloud computing application in education.

\section{Geographical Area}

The following chart shows the classification of articles based on the geographical area. 


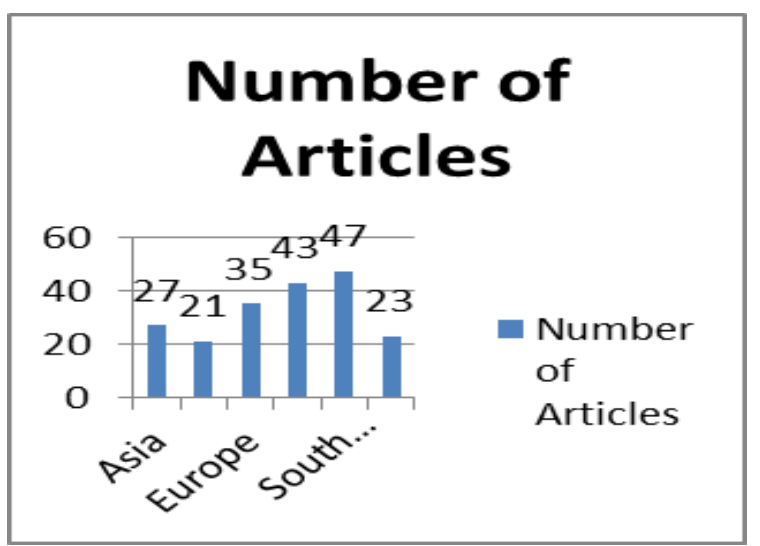

Figure 3: Classification of articles based on geographical location

Figure 3 shows South America is having highest number of research articles (47) publication and Australia is having lowest number of research articles (21) out of Asia (27), Australia (21), Europe (35), North America (43), South America (47) and Africa (23) for cloud computing application in education sector.

\section{Types of Research Frameworks}

The following chart shows the articles covered based on the types of research frameworks used in the study.

\section{Number of Articles}

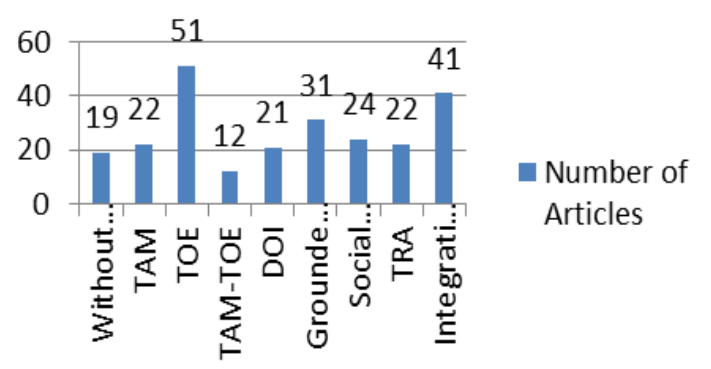

Figure 4: Classification of articles based on Types of Framework

The different types of research frameworks identified in the last nine years are Technology-Acceptance-Model (TAM), Technology-Organization-Environment (TOE), TAM-TOE, without any theory, Diffusion-of-Innovation (DOI), grounded theory, social cognitive theory, Theory of Reasoned Action (TRA) and Integration of more than one theory. Figure 4 shows out of these there are highest number of papers on TOE (51) and lowest number of articles on TAM-TOE (12) integration model.

\section{E. Research Area}

The following pie-chart shows the number of articles covered based on the research area studied.

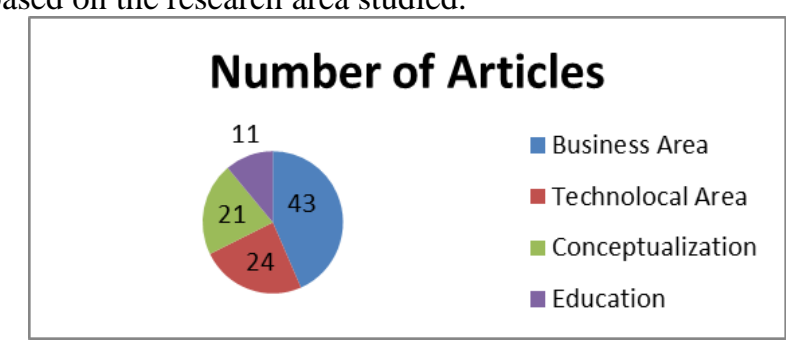

Figure 5: Classification of articles based on Research Area
The articles were searched from four areas of research: business aspect, technological aspect, conceptualization of cloud computing and education sector. Figure 5 shows highest number of articles in business aspect (43), next technological aspect (24), conceptualization of cloud computing (21) and lowest one is in education sector (11). Hence, it shows educational aspect is having very few number of research articles, which needs much studies needs to be done in this area of cloud computing.

\section{CONCLUSION WITH FUTURE SCOPE}

The study identified cloud computing application in education sector in India is very rare and yet a lot of work needs to be done in this field. Hence, academicians and practitioners should explore more in this area of cloud computing. The study is based on the peer-reviewed journal articles in the area of cloud computing application in education from 2010 to 2018.The objective was to classify the articles based on the meta-analysis. The literature review might not be declared as comprehensive and allows the research in the current area of cloud computing adoption. The study identified the peer-reviewed articles in last nine years which can be broadened in future. The meta-analysis is done based upon some key-word search which could be done using some other classification criteria. The articles were searched from two databases which might be covered from remaining four databases. The peer-reviewed articles were considered for the study. Hence, there is a scope of study covering the reports, conference papers, thesis and books.

\section{REFERENCES}

1. Abdollahzadehgan. A. et al. (2013). The Organizational Critical Success Factors for Adopting Cloud Computing in SMEs. Journal of Information Systems Research and Innovation, pp. 67-74.

2. Bergh, D. D., Aguinis, H., Heavey, C., Ketchen, D. J., Boyd, B. K., Su, P., Lau, C. L. L., \& Joo, H. (2016). Using metaanalytic structural equation modeling to advance strategic management research: Guidelines and an empirical illustration via the strategic leadership-performance relationship. Strategic Management Journal, 37(1), 477-497.

3. Duncombe, R., \& Boateng, R. (2009). Mobile Phones and Financial Services in Developing

4. Countries: a review of concepts, methods, issues, evidence and future research directions. Third World Quarterly, 30(7), 1237-1258.

5. Johnson, R. B., \& Onwuegbuzie, A. J. (2004). Mixed methods research: A research paradigm whose time has come. Educational Researcher, 33(7), 14-26.

6. Judge, T. A., Thoresen, C. J., Bono, J. E., \& Patton, G. K. (2001). The job satisfaction-job performance relationship: A qualitative and quantitative review. Psychological Bulletin, 127(1), 376-407.

7. Kshetri, N. (2010b). Cloud computing in developing economies. Computer, 43(10), 47-55.

8. Kuyoro S.O.,Ibikunle F.,\&Awodele O. (2011). Cloud computing and security issues challenges. International Journal of Computer Networks (IJCN), 3(1), 247-255.

9. Levy, Y., \& Ellis, T. J. (2006). A systems approach to conduct an effective literature review in support of information systems research. Informing Science Journal, 9 (1), 181-212.

10. Moodley, S. (2003). Whither business-to-business electronic commerce indeveloping economies? The case of the South African manufacturing sector. Information Technology for Development, 10(1), 25-40.

11. Mohsin Nasir (2012). Cloud Computing: Overview \& current research challenges. IOSK Journal of Computer Engineering, 8(1), 14-22. 


\section{Cloud Computing Application in Education}

12. Priyadarshinee, P., Jha, K., \& Raut, R (2015). Cloud Computing Adoption in SMEs: A Literature Review. In Twelfth AIMS International Conference on Management.

13. Qi Z., Lu C., \& Raouf B. (2010). Cloud computing: State of the-art and research challenges. The Brazilian Computer Society, 1(1), 7-18.

14. Sabi, H. M., Uzoka, F. M. E., Langmia, K., \& Njeh, F. N. (2016) Conceptualizing a model for adoption of cloud computing in education. International Journal of Information Management, 36(2), 183-191.

15. Senyo, P. K., Addae, E., \& Boateng, R. (2018). Cloud computing research: A review of research themes, frameworks, methods and future research directions. International Journal of Information Management, 38(1), 128-139.

16. Shaw, J. D., \& Ertug, G. (2017). The Suitability of Simulations and Meta-Analyses for Submissions to Academy of Management Journal.

17. Sultan, N. (2010). Cloud computing for education: A new dawn? International Journal of Information Management, 30(2), 109-116.

18. Svantesson, D., \& Clarke, R. (2010). Privacy and consumer risks in cloud computing. Computer Law \& Security Review, 26(4), 391-397.

19. Yang, H., \& Tate, M. (2012). A descriptive literature review and classification of cloud computing research. Communications of the Association of Information Systems, 31(1), 35-60.

\section{AUTHOR PROFILE:}

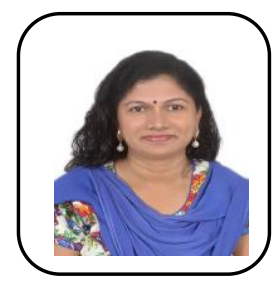

Pragati Priyadarshinee holds a Ph.D. in "Cloud Computing" from National Institute of Industrial Engineering (NITIE), Mumbai and M.Tech in IT from IIIT, Allahabad. She is having 12 years of experience in teaching and research with a number of peer reviewed publications both in International Journals of repute and Conferences. She is currently working as an active reviewer of "Journal of Cleaner Production" and "International Journal of Information Management". Currently she is working as an Assistant Professor with CBIT Hyderabad. 